\title{
Tutorial teaching assistants in the classroom: Similar teaching behaviors are supported by varied beliefs about teaching and learning
}

\author{
Renee Michelle Goertzen, Rachel E. Scherr, and Andrew Elby \\ Physics Education Research Group, Department of Physics, University of Maryland, College Park, Maryland 20742, USA
}

(Received 19 October 2009; published 7 April 2010)

\begin{abstract}
As part of a long-term program to develop effective, research-based professional development programs for physics graduate student teaching assistants (TAs), we first identify their current classroom practices and why they engage in these practices. In this paper, we identify a set of teaching practices we call "focusing on indicators," which occurs when TAs use signs such as key words or diagrams as evidence that students understand the target idea; these indicators are more superficial than a detailed explanation. Our primary finding is that although the three TAs discussed here share a common behavior, the beliefs and motivations that underlie this behavior vary. We argue that TA professional development focused on changing these TAs' focus-on-indicator behavior is unlikely to be effective. Instead, responsive TA professional development will need to address the TAs' beliefs that guide the observed classroom behavior.
\end{abstract}

DOI: 10.1103/PhysRevSTPER.6.010105

PACS number(s): 01.40.Fk

\section{INTRODUCTION}

The physics education community has devoted decades to producing research-based undergraduate curricula that help students construct their own physics knowledge. At the undergraduate level, there are now many successful, researchbased curricula and instructional methods available [1-4]. While the developers of these curricula have carefully studied how written material should be organized and how students should best interact with these materials, much less attention has been given to those who instruct using the curricula. At many universities, a significant portion of students' physics classroom instruction comes from the graduate student teaching assistants (TAs) who lead the discussion sections that supplement large lecture courses. There has been little published research on such instruction by teaching assistants, be it descriptive or prescriptive. Both researchers and doctoral students themselves have identified a need for more effective, research-based TA training for graduate students [5-7].

Physics education research has demonstrated the benefits of understanding students' physics ideas before instruction so that we can develop lessons that build on them $[8,9]$. Similarly, understanding the initial states of TAs provides the basis for professional development that considers the knowledge and resources that TAs already have. Research to identify TAs' teaching ideas and practices should ideally include both observations of TAs' specific instructional actions and reports from TAs of their goals and motivations, so that we may learn both what they are doing and what they are trying to do.

Our own detailed observations of TAs in tutorial classrooms have led us to identify a set of approaches to teaching that share a common characteristic we call "focusing on indicators." The indicators that TAs seek vary, but are all more superficial than detailed explanations-for example, key words, a particular type of reasoning, or correct answers. We find evidence that each TA's focus on indicators stems from his beliefs and attitudes about tutorial teaching. However, their similar behaviors do not stem from similar beliefs. Our primary finding is that different TAs with similar focus-on- indicator behaviors are motivated by different underlying values for tutorial teaching. For example, one TA in our study believes that students should be given the benefit of the doubt; another believes that students deserve to hear the right answer from the TA. In the classroom, however, these TAs interpret and respond to students' correct answers in a similar way.

The implications of this result for TA professional development are twofold. First, TA supervisors are not likely to be able to "read off" TAs' beliefs based on their teaching behaviors; there is not a one-to-one correspondence. Second, TA supervisors who want to help TAs value tutorial teaching should not expect to do so by guiding TAs' behavior: helping TAs learn to ask questions will not necessarily help them share tutorial developers' motives for questioning. The most promising means for improving TAs' teaching is to respectfully explore and engage with TAs' potentially productive beliefs about teaching.

\section{BACKGROUND}

\section{A. Previous research}

Research on graduate TAs is currently a small but growing field. In order to consider as much of the relevant literature as possible, this section will include research on TAs in all of the STEM (science, technology, engineering, and mathematics) disciplines. This research has rarely produced the sort of detailed descriptions of TAs' behavior that could inform professional development. Some professional development (PD) programs report changes in TAs' beliefs, but do not examine whether these result in changes in fine-grained behavior in their classrooms.

\section{Much of the research on STEM TAs does not characterize their teaching}

Much of the research on STEM TAs has taken place within studies of the professional development programs for these TAs [10]. These studies often focus on detailed descriptions of the content of the programs. The effects of these programs on the TAs are either measured through surveys, 
written assignments, or interviews that assess reported changes in the TA's attitudes about teaching or learning [11-15] or provide informal evaluations of TA experiences $[16,17]$. The studies using surveys have provided limited glimpses of TA changes after PD, including more appreciation of the importance of attention to student ideas [18], increases in beliefs that skills learned in teaching can improve their research [11], and more awareness of physics education research $[12,15]$.

An example of a study assessing a PD program for TAs is Ishikawa et al. [18]. The authors used written assignments and a free-response survey to assess the beliefs of two cohorts of TAs before and after a PD course and found that some TA beliefs changed. In the first cohort, they found that TAs were more aware of student difficulties and the responsibility of instructors to notice these difficulties. An example of the type of response demonstrating this awareness was one which said "...a good teacher is one who intuitively knows where students are going to have trouble in understanding a topic and is ready with helpful hints when they hit those bumps.'"[[18], p. 6]. In the second cohort, the researchers found that TAs were less likely to relate good teaching to the ability to communicate knowledge. This finding was based on the fact that this was mentioned more in the initial assessments than in the final ones. These evaluations show that how TAs talked about their teaching was altered, but they do not address the question of whether the TAs' classroom practice changed.

Surveys provide a way to assess larger groups of TAs and to identify shared knowledge or beliefs. However, a limitation of analyses built primarily on written materials is that they cannot address the question of how knowledge or beliefs affect practice. The use of self-reported classroom analysis is problematic not only because the TAs' self-reports may not accurately reflect their teaching practices, but also because it may be difficult for the researchers to identify influences that the TAs do not recognize themselves. Multiple studies in math and science education demonstrate that teachers' self-reports of their behavior and beliefs do not consistently correlate with their classroom actions [19-25].

\section{Observational studies in the classroom characterize TAs' teaching with broad categories}

Observations of TAs' teaching have been used to assess the effectiveness of PD programs [26,27] and to better understand the TA or graduate experience overall [28,29]. These observations are often limited to a few hours per semester and characterized by general descriptions of the TA's individual teaching style [26,28,29]. A typical example is found in Belnap's study of factors influencing the practice of three math TAs [28]. The following excerpt is his reflections of the three classes he observed when a TA, Lisa, taught:

From the very beginning, Lisa's teaching style consisted of lecture, which she would begin shortly after giving a few announcements or reminders. Initially, this lecture incorporated a cycle of instruction, illustration, and assessment. First, she would provide definitions and explain ideas, then she would show various examples, and finally, she would lead the class through sample problems, quizzing them occa- sionally for an answer or for single steps in a problem [[28] p. 50].

This characterization gives a general idea of the types of activities one might observe in Lisa's class. However, there are many details that could be included to give a better understanding of Lisa's teaching, including whether examples and questions are chosen in response to student ideas or how much reasoning needed to be provided for an answer to be considered correct.

\section{TA behavior that appears similar can mask important differences in goals, motivations, and beliefs}

Research by Speer provides a rare example of how examining TAs' beliefs about teaching can help researchers understand specific teaching behaviors [30]. Her work suggests that typical assessments of instructor beliefs, especially surveys, are insufficient for understanding the individual instances of classroom practice. Speer studied two graduate mathematics TAs whose shared beliefs included: (1) the idea that learning mathematics requires complex problem solving in addition to practicing procedural skills like differentiating and (2) the idea that part of learning mathematics is learning about the relationships between ideas. However, the detailed case studies of the two students, Zachary and Karl, show important differences in their beliefs. A strength of this study is the fact that the primary data source was interviews in which the TAs discussed video clips from their classes, which allowed the researcher to better understand the TAs' explanations of their actions and motivations within the context of specific examples.

One example of a dissimilarity uncovered only through the video interviews is in the TAs' beliefs about questioning. Although both TAs thought that it was important to question students, Zachary felt that questions were necessary to check the strength of student understanding and to provide a mechanism for students to learn. Furthermore, when students were unable to answer his questions, he considered this evidence that they did not understand the concept. As a result, his questions were often motivated by his desire to understand the students' difficulties and to help them identify and overcome their problems themselves. On the other hand, Karl asked questions to model the behavior he wanted students to emulate when problem solving and to monitor their learning so he knew when to intervene. This second action was necessary because it was important to Karl that students not stray too far from the material that he had prepared and that all students complete the same problems. As a result of his corrections, students in Karl's class spent less time exploring why their original answers were incorrect than in Zachary's class. In addition, Karl often assumed that a student's lack of a correct answer was due to low confidence or a momentary "forgetting" of what they already knew. This meant that he had fewer chances to find the inadequacies in his students' conceptions.

These detailed case studies point out that surveys that ask about teachers' beliefs, even if they are specific, may miss potentially significant differences that motivate different teacher behavior. Further, observations of classroom work provide a way to see how these belief differences correspond 
to classroom teaching styles. By carefully examining Zachary's and Karl's teaching behaviors and correlating those behaviors with the TAs' reports of their intentions, Speer accounts for the different classroom environments that Zachary and Karl created.

Speer's analysis of Karl's beliefs is drawn from his own discussions of particular examples of his teaching, which allow us to better understand how he justifies his behavior. What is still lacking is examination of how Karl's students influence his interactions with him or how the context of the situation affects Karl's actions. An example is an analysis of an episode where Karl notices a student group's mistake and points to a portion of their solution, asking, "Does this work? Is this a solution?" One of the students, Greg, replies, "We want to say no," and laughs. Then a second student, Buddy, offers an incorrect answer to Karl's next question, followed by Greg offering a correct one.

Since Karl assumed students understand when they state correct answers, there was no reason for him to ask Greg why it was that he wanted to say no. Since he did not necessarily attribute a lack of understanding to the students when they stated an incorrect answer, he was not necessarily compelled to follow up on Buddy's error [30].

This analysis does explain how Karl responded to the students' statements, but it does not include an account of how those student responses influenced him. Instead, the explanation of Karl's behavior is primarily based in his consistent beliefs about how students learn and what counts as evidence that they understand.

We argue that the best way to understand TA classroom practice is to observe them while they are actually teaching and to analyze their interactions with students in detail, giving more than just broad-brushed generalizations about their teaching. Our analysis will show why such fine-grained analysis is necessary: TA behavior that appears similar can originate from different kinds of beliefs, which suggests the need for professional development that is responsive to individual TA differences.

\section{B. Tutorials}

The TAs we studied taught discussion sections for the introductory algebra-based physics course at the University of Maryland. As part of a comprehensive reform project [31], the discussion sections, which had previously been traditional TA-led recitation sections, were replaced by tutorial sessions. In these sessions, students work in small groups on worksheets that emphasize conceptual understanding of physics. Each class has six tables at which groups of four students work together. Two TAs circulate through the room, working with various groups as needed.

\section{Tutorial worksheets}

The tutorials we use were developed at the University of Maryland and use the format established by the University of Washington Physics Education Group [3]. University of Maryland tutorials are designed to emphasize the reconciliation of everyday intuitive thinking with the formal science knowledge students are learning in the classroom. They also encourage students to explicitly consider and discuss their epistemological beliefs about learning physics [32]. Each tutorial addresses one conceptual topic in the first semester of algebra-based introductory physics [33].

\section{Tutorial preparation meetings}

The TAs assigned to teach tutorials are required to attend a weekly one-hour preparation meeting. This meeting takes place in the same room where the TAs teach. TAs sit at the tables in groups of two to four people. The TA instructor usually leads a discussion of pedagogical issues arising from the previous week's tutorial. Following this discussion, the TAs work through the upcoming tutorial in their groups. In these meetings, the TA instructor attempts to convey the idea that the TAs' job is to facilitate learning by asking questions, rather than providing long explanations. These methods are explicitly discussed at the start of the semester, and the instructor models these behaviors while the TAs work through the tutorial as their students would. First-year TAs, in addition, attend approximately eight hours of instruction focusing on general teaching strategies, including classroom management and policies.

Our weekly tutorial meetings allow TAs to familiarize themselves with the tutorial they will be teaching and provide them with instructions about common student difficulties in each tutorial. These meetings are designed to accommodate the strengths and constraints TAs have: their limited time, advanced content knowledge, and minimal pedagogical content knowledge. However, our PD program fails to account for the ideas and experiences that TAs bring to their teaching, and we expect that most TA PD programs could be improved by considering these.

\section{Theoretical framework}

\section{Fine-grained understanding of TA practice can benefit professional development}

Up to this point, the training that we have offered our TAs, like much of the PD offered to TAs in science departments nationally, has not been sufficiently research-based. Research on K-12 teacher professional development might provide a good starting point, since graduate students are typically novice instructors. However, graduate students are in some ways distinctly different from K-12 teachers. First, they usually identify themselves primarily as scientists and only secondarily (if that) as teachers, and thus see their primary job as research rather than instruction. Second, TAs often receive little if any pedagogical preparation: the Maryland program is typical in offering only the weekly one-hour tutorial preparation session described above, supplemented by intermittent seminars focusing on general teaching strategies,

In order to understand the kind of training TAs would most benefit from, we need to better understand the instructional environment in which they work. We need to identify the types of decisions TAs make as they teach, what sort of information they notice and use to make these decisions, and how they and their students negotiate what it means to learn 
physics through tutorials. Most importantly, we need to know why TAs make these decisions so that the professional development programs we create for them can be responsive to their current knowledge and beliefs about teaching. We seek to build this understanding by examining the minute-byminute experiences of TAs as they teach.

\section{Framing influences behavior}

Our approach for this type of fine-grained analysis is based on framing, a concept developed by sociologists and linguists to study people's expectations about their activities and how these expectations influence their behavior [34-37]. The sociologist Goffman describes the study of framing as a search for answers to the question of "What is it that's going on here [[35], p. 8]?" Frames are what people use to make sense of the activities going on around them, and to help them decide what actions are appropriate in a given situation. Individuals are always framing what they are doing, albeit mostly unconsciously, and communicating that frame to their fellow participants. The process of framing is influenced by the expectations that the people involved in the activity bring with them. These expectations are built up from past experience and allow people to use their experiences to make sense of what is going on now.

To see how a person's framing affects his behavior, consider a father at his child's soccer game. He might frame his activity as rooting for a sports team or as nurturing children. How he frames the soccer game will lead him to notice different things: if he is rooting for a sports team, he may pay attention to who is scoring points, whereas if he is nurturing his child, he may note who is having fun. This would also affect his behavior, leading to more partisan cheering in comparison to general encouragement. This example also demonstrates the role of context in framing, because a league championship might be framed as a competition, while an unscored scrimmage is more likely framed as an opportunity for fun. Contextual cues can also cause a change in frames, such as when a father rooting for the team suddenly focuses on his child's wellbeing when she is injured.

When we analyze TAs' teaching, we use evidence such as how much people talk, the types of questions they ask, the conversational pace, their body positioning, gestures, and register (word choice, syntax, pitch, etc.), to infer how they are framing the situation. We look for additional support for these analyses from the ways TAs talk about their teaching in interviews. While we use TAs' statements to corroborate our ideas about how they frame, we are careful not to assume that these will necessarily match their actions. This is because the relationship between framing and beliefs is not directly causal, as the next section explains.

\section{Beliefs support but do not determine framing}

We use the term beliefs as a general phrase to describe the declarative knowledge that TAs have about teaching and learning. (For our purposes, "beliefs" are not technically distinct from knowledge or values; while we acknowledge distinctions that other researchers have made [38,39], these shades of meaning are not critical to our argument.) We ex- pect that in general, beliefs are context dependent: the context can influence which beliefs are activated (implicit dependence) [40], and/or people may explicitly decide that certain beliefs are only true in particular circumstances (explicit dependence). People can hold contradictory beliefs that are nonetheless quite stable in particular contexts. For example, most people think lying is wrong, but complimenting someone's new hairstyle, regardless of its aesthetic appeal to you, is generally considered acceptable. Similarly, a TA could express a belief that tutorials are too easy for students, and yet also think that students cannot do them. Thus, when we claim that a TA's framing is supported by stable beliefs (as we will in the data presented below), we also know that he or she has other stable beliefs, which in a different context could lead to a different framing. (For example, we have discussed the plausible relationship between TAs' buy-in and their social and environmental context in another work [41].) This concept of beliefs differs from much previous work on beliefs and knowledge, which views beliefs as active across many circumstances $[22,42,43]$. It also extends our own previous work, in which a "beliefs" approach was associated with a unitary cognitive theoretical framework and was contrasted with the context dependence of frames [44].

In our approach, stable beliefs play a supporting role in framing. In the above example of a soccer dad, a man who believes in the need to develop toughness in a competitive world would more likely frame a soccer game as a partisan event than a man who believes that strong children are products of unconditional love. The more stable the belief, the stronger its relationship is likely to be to the framing of any particular situation. Beliefs can only influence framing, though: they cannot determine it, because that would exclude the effect of context, such as the other participants' responses.

How a TA frames teaching is influenced both by his or her negotiations with students about what kind of activity they are all engaged in and by the stable beliefs that the TA has about teaching and learning. The TA may be guided by beliefs about what would be appropriate in this situation, but the students' responses then either support or undermine the TA's actions, so that together they construct a shared framing of the activity. (This is not to say that participants always have the same framing: mismatched framing is common, and can lead to humor, conflict, or "talking past each other," depending on whether the participants recognize that they are framing in different ways [35].)

By using framing to analyze how TAs teach, we attend to the variability within an individual TA. TAs are not firmly categorized as possessing a certain type of belief corresponding to their teaching practice. Rather, the goal is to identify the different ways TAs can behave in the classroom, and the reasons that, for example, they might lecture in one instance and ask probing questions in another. Explanatory power is sought in instances across TAs, rather than within a single TA. We generate coherent explanations of individual episodes using framing, but we do not expect TAs to behave in a globally consistent way. 


\section{DATA COLLECTION AND ANALYSIS}

\section{A. Participants}

During the fall semesters of 2006 and 2007, University of Maryland graduate students who were tutorial TAs for the introductory, algebra-based physics course (Physics 121) were invited to participate in our study. 15 of 21 TAs consented to be interviewed twice, at the start and end of the semester. Graduate students conducting physics education research were excluded from the study. Many of the TAs had their classes videorecorded. We selected classes to record based on scheduling convenience and not on the basis of the TAs' teaching or past experience. During 2006, we also recorded the weekly meetings in which TAs prepared to teach the following week's tutorial.

Most of the TAs who taught tutorials were first or second year graduate students whose primary purpose in teaching was to support themselves financially before joining a research group. The majority were in their early twenties. The research university they attend is in a suburban metropolitan area and has a large undergraduate and graduate physics program. The only women assigned to teach tutorials during the two semesters of this study were physics education graduate students, who were excluded from the study. Thus, all the TAs in the study are male. (This is not an unusual situation at UM, where women made up $12 \%$ of the physics graduate population in 2005 [45].) Almost half of the TAs who participated in the study were not native speakers of English; however, all but one communicated easily in English.

We chose a smaller group of TAs to study in greater detail. The five "focal TAs" were selected because they were articulate about their teaching during their interviews or during TA preparation sessions. We watched multiple episodes of the TAs interacting with their students, seeking to describe and explain the TAs' behavior.

The three TAs discussed in this paper, Alan, Julian, and Oscar, were focal TAs. They are demographically representative of the larger pool of TAs: they were all in their first or second year of graduate school and two were non-native English speakers. We consider the examples discussed here to be representative of the larger sample of their teaching that we observed, although we observed episodes that we would not characterize as "focusing on indicators." We did not see all TAs focusing on indicators while they were teaching; one notable exception was a TA who had previously taught high school physics.

During our data collection, we became aware that TA support (or "buy-in") for the tutorials that they were teaching varied. In a separate publication [41], we characterized the buy-in of the 15 TAs we studied and discussed how the context in which they worked appeared to influence their buy-in. The three TAs discussed here are among those that did not buy into many aspects of the tutorials.

\section{B. Design}

When developing a case study, we use video recordings of TAs' classes to gain information about specific teaching situations and interviews with the TAs to gain understanding of their beliefs and attitudes about tutorials. We watch video clips of TAs teaching and seek to provide plausible framings that might explain their classroom behavior. We then analyze interviews with those TAs, seeking statements that provide insight into why TAs might be framing situations in the ways we see, and cycle iteratively between classroom video and interviews to confirm or disconfirm our hypotheses. The two different data sets allow us to investigate relationships between the TAs' behaviors in individual interactions and their beliefs about teaching in tutorial classrooms.

This method of iteratively comparing our analysis of a TA's teaching practice and beliefs about that instruction contrasts with many studies of TAs and teachers, which attempt to first understand the instructor through data such as interviews or written assignments, and then (in some cases) to compare these assessments to actual behavior. In the next section, we discuss an example of TA behavior that provides explanatory power across examples of several TAs' teaching.

\section{RESULTS: USING FRAMING TO UNDERSTAND TAS' FOCUS ON INDICATORS}

As physics graduate students teach tutorials, they can frame their activities in different ways. For example, they might frame their job as helping students to look for consistency in their answers, or as an opportunity to assess students' understandings of physics concepts. One way in which TAs seem to understand their job in the tutorial classroom is as a search for indicators that students have the appropriate knowledge. This focus on indicators is their understanding of the local activity, and is a nested subroutine situated in the way they more globally frame their jobs as TA instructors. The indicators they seek vary, but are all more superficial than detailed explanations-for example, key words, a particular type of reasoning, or correct answers. ${ }^{1}$ TAs ask questions of and interact with students toward achieving their often-tacit goal of getting students to generate an indicator. When students have produced the relevant indicators, the TAs see this as evidence that the students have the necessary knowledge and the TAs' job in that moment is finished. In general, focusing on indicators results in TAs depending on evidence of understanding that physics education researchers would consider insufficient.

In these cases, the TAs in the episodes we will discuss would not answer the question, "What is going on here?" by saying "I'm focusing on an indicator." Instead, their answer might be that they are "giving a hint" or "making sure the students understand." But among these explicitly acknowledged ways of framing we see a set of behaviors that is locally consistent: the students provide feedback about their understanding that we might not consider convincing, but which the TA accepts as showing that the students understand. The students' responses develop positive feedback

\footnotetext{
${ }^{1}$ It may be that "focusing on indicators," would be best considered as a subroutine of behaviors present in various ways TAs frame their teaching, rather than as a frame itself. For our purposes, attending to key words or numerical answers seems qualitatively different than attending to detailed explanations and that is the characteristic that distinguishes a "focusing on indicators" behavior.
} 
B. Suppose a small ball rolling along a track produced the motion represented on the graph at right. What might the track have looked like? Sketch an arrangement of tracks you might set up to produce that motion.

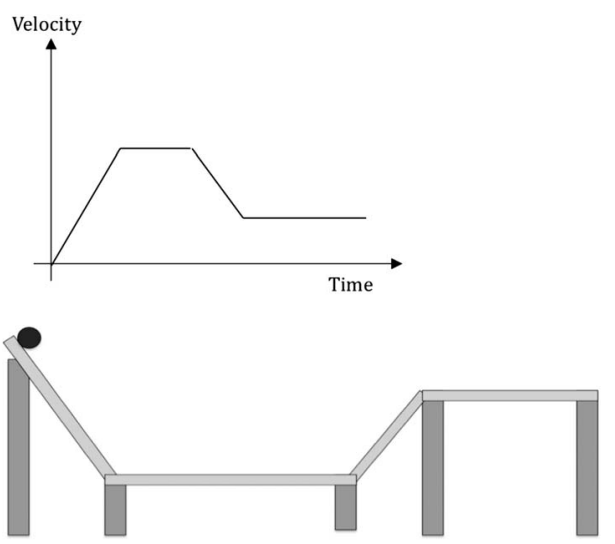

FIG. 1. A tutorial problem showing a velocity-time graph and the track that is the correct answer.

loops with the TA's beliefs and expectations to support the TA's focus on indicators, creating a relatively stable and coherent sense of the nature of the activity.

Although each TA described below can be characterized as "focusing on an indicator," there is behavior variation within individual TAs. For example, there is variability in the types of indicators (numerical answers, statements, etc.) that a particular TA uses as evidence of knowledge. This variability is to be expected: the context of the particular situation (which tutorial a TA is doing, the group of students with whom he is interacting, etc.) may encourage different behaviors within similarly framed activities. The consequences of such situational variability will be seen in the first two examples, which both focus on a TA named Alan.

\section{A. Alan focuses on indicators: Correct answers}

At the time of this episode, Alan was a first-year graduate student with experience in private tutoring, but no prior experience serving as an instructor for a class. In the episode below, Alan verifies the students' answer to a tutorial question. In doing so, he uses a sketch that students have drawn as an indicator of the students' knowledge. Because he is focused on the answer, he fails to notice hints that not all of the students may be solid in their understanding, and thus that it may not be a good indicator of their knowledge.

In this episode, a group of four students are working on a problem, which presents a velocity-time graph generated by a rolling ball. The tutorial asks the students to draw a track that would produce the motion in the graph [[46], p. 688]. Figure 1 shows the problem and a track that is a correct answer. Note that in this case, the shape of the track is almost a mirror image of the velocity graph.

In the following episode, the students have just drawn the track. As Alan walks by the table, S4 asks him to look at their solution. Alan looks at the track and then states that it is correct. He cautions the students that not all tracks will be the mirror image of the corresponding motion graph and ends by pointing out a small correction to S1's sketch.

1 S4 How does this look to you?

2 [Alan looks at S4's paper]

3 S1: It's like the opposite of the...

4 Alan: Well, yeah, that's what it ends up

5 looking like. I mean, I'm not sure that

6 you can always say that it will be the

7 exact opposite of... Maybe this one, in

8 this case it happens to be.

9 S3: Okay.

10 Alan: But, I mean, I'm guessing you

11 guys sort of thought this one through

12 and sort of figured out-

13 S3: Yeah.

14 S4: Yeah.

15 Alan: -why it would look like that.

16 S4: Yeah, definitely.

17 S1: Uh-huh. Just that it rolls like down

18 the hill-

19 Alan: Mm-hmm.

20 S1: -and straight-

21 Alan: Yeah.

22 S1: -then up the hill-

23 Alan: Mm-hmm.

24 S1: -and then flat again.

25 Alan: Right. Yeah. The one thing you

26 want to be careful about, I, I actually

27 know exactly what you meant, so this is

28 right. But, like, you really want this one

29 to be higher than this, because

30 otherwise it won't get up.

31 S4: Yeah, I sort of, I changed it a little.

32 I extended it.

33 Alan: I mean, as long as you realize that

34 has to be true, don't worry about it too

35 much. But...

36 S1: Mm-hmm.

37 S4: Yeah.

38 Alan: It's just conservation of energy.

39 You guys haven't seen that in class yet.

40 Alan: The ball won't actually-

41 S1: Make it.

42 Alan: go further up than you had it in

43 the first place.

44 S3: Yup.

45 [Alan leaves.]

\section{Alan's frame: Checking the students' answer}

Alan would probably describe what he is doing in this episode as "checking the students' answer." After all, the interaction begins when S4 catches Alan's attention as he is walking by the table and asks him whether their solution is correct. S4 then shows Alan the picture of the track they have drawn, which presents Alan with an indicator of what the students are thinking. Alan does not have to rely on this 
picture to assess students understanding; he could ask for explanations or probe with question about similar situations. Instead, Alan tells them their answer is correct. He does not ask the students to explain their answer, and although S1 offers a description of the track's appearance, this does not tell Alan anything about how the students decided what the track would look like or how it corresponds to the graph they used to construct the track.

There are several pieces of evidence that Alan is not focusing on the substance of the students' ideas. As mentioned before, he does not ask for clarification. When listening to S1's description, he says "mm-hmm" and "yeah" repeatedly (lines 19, 21, and 23), and these affirmative sounds are spoken at almost the same time as her statements. This suggests that he is not listening closely, as his responses happen so quickly that there is little time for Alan to have thought about what S1 has said. His statements of "I'm guessing you guys sort of thought this one through," and "I actually know exactly what you meant" (lines 10-11 and 26-27) also show that he thinks he already correctly understands what the students are thinking.

When Alan says that he assumes the students have thought through the problem sufficiently, he may also be indicating that he expects that the students will tell him if they need help. His confidence in their ability to assess their own understanding and his belief that they mostly understand the material comes through in the way Alan corrects S1's drawing at the end of this episode. After looking at S1's drawing during her explanation, Alan cautions that she should be careful that one side of the track is higher than the other (lines 28-30). This is apparently different than what she has drawn, because she erases and redraws part of her picture immediately after he says that. The way that Alan phrases this correction, "I mean, as long as you realize that has to be true, don't worry about it too much," (lines 33-35) shows that he sees this error as a small matter, perhaps a detail that she forgot, rather than as a signal that she does not really understand the solution.

Alan frames this activity as checking the students' answer, and the ways the students interact with him support his framing. When Alan is talking, the students spend most of their time either looking at him or at the solution S1 has drawn and frequently say, "Yes," or "mm-hmm" (lines 36, 37, 44). These are signals that Alan may notice and interpret as evidence they are paying attention to the conversation. When he states his assumption that they have "thought this one through" (lines 10-12), they agree (lines 13-14) and do not ask further questions, suggesting that they are satisfied that their answer is correct. Moreover, S4's initial question to Alan conveys what he wants to know from Alan, which is the correctness of their answer. Thus, the students also frame this activity as verifying their answer with the TA, and a shared, stable understanding of the activity is maintained.

The students drew a picture that is mostly correct, and they may in fact have a deep understanding of the velocitytime graphs. In this case, however, the available evidence of student thinking is not extensive, and Alan does not solicit more. His focus on indicators does not mean that Alan is incorrectly assessing student knowledge, but rather that the evidence he uses, the students' drawing, is insufficient.

\section{One of Alan's beliefs: Instructors should give students the benefit of the doubt on conceptual questions}

Alan's use of a drawing as an indicator of student understanding is consistent with his beliefs about what good teaching looks like and how the tutorial fails to provide a good teaching environment. Specifically, he feels that failing to acknowledge and support students' correct answers is bad teaching. He asserts in his interviews that the tutorial is unfair when it expects students to make mistakes, saying, "Basically, it assumes that... they were stupid... I'm seeing that every time I do the tutorial, there's... at least one group every time who doesn't make the stupid mistake. And then they feel, actually, kind of offended." His personal experiences support this idea: "I remember being in high school and... my group goes through it (the assignment) quickly, and then it's very frustrating to be in a group where things went well, and the assumption behind everything the teacher is doing is that everybody will screw up." He thinks the tutorials are discouraging students when they assume the students will make errors, and he remembers feeling that way himself as a student. He reiterates that, "There are a lot (of tutorials) that ask questions in what I think... is a pedagogically dangerous way." Throughout his interviews, Alan's dedication to teaching and his desire to help his students is clear. He has convictions about the correct way to teach, and the tutorials contradict these.

One way to describe how Alan might justify what he is doing is that he is "giving students the benefit of the doubt." He sees some evidence that they understand the material, and it is important to him that teachers support students' correct answers rather than assuming that they are wrong. As a result, he offers a correction to the drawing rather than questioning the students about the incorrect part of it or probing for more details. The students may consider this correction minor, and are content to have their answers confirmed, so they do not ask for additional help. By giving students the benefit of the doubt, Alan does not have a chance to hear deeper reasoning that might challenge his assessment that they understand. Because both the students and Alan are satisfied with the encounter, no one challenges the assumptions anyone else is making, and a stable situation is established.

Alan's actions are also influenced by his belief that that tutorials were not that challenging for his students, explaining, "I thought the problems they were being asked to work on, they didn't really have that much trouble with... one could have raised the level of the problems they were asked to do." He suggested that his students struggled much more with problem solving than with the concepts in tutorials, saying, "I thought... when we were originally presented with this stuff that everybody would be struggling with this... That's not happening... I've seen a lot of people who do already understand first of all, and second, I'm seeing massive confusion on what we would call traditional physics." The problem the students are working on in this episode is conceptual, and Alan's behavior in this episode is aligned with his belief that this kind of problem will not challenge his students and that they should not be exerting a great deal of effort on problems like this.

In this example, Alan focused on an indicator of student understanding - in particular, on the (mostly) correct answer 
a student had written on her worksheet. This indicator, while not without value, is not a reliable sign of student knowledge. Alan's attention to this indicator is consistent with his belief that students who might have a good understanding should be given the benefit of the doubt. His values for tutorial teaching motivate his specific teaching actions. His selective attention to the indicator, along with reinforcement from the students, strengthens his conviction that the students probably understand the physics.

\section{B. Alan focuses on indicators: Student affirmations}

A focus on indicators can produce a variety of different behaviors, even for the same TA. A second example of Alan's teaching illustrates this. In it, two students are working on a problem in the seventh tutorial (shown in Fig. 2) in which they are asked to draw a free-body diagram of a block at the point when it has slid to the top of a loop-shaped track [47]. Alan determines that they cannot answer the question, and goes on to give them a hint. This time he focuses on students' affirmations to determine that they understand his hint.

In the following clip, the students call Alan over and explain that they do not know whether the normal force on the block from the track is pointing up or down. This situation is difficult for students because the correct answer is both unusual (this normal force is aligned with the gravitational force rather than opposing it) and counterintuitive (how does the block stay up if the only forces on it point down?). Before he can address their question, Alan is interrupted. When he returns to the table, he explains to the students that an object moving in a circle must experience a centripetal acceleration, which he labels " $v$ squared over $r$." He indicates that this is a hint, not the answer to their question, but that it is information that they can use to help answer their question.

$1 \mathrm{~S} 2$ : I'm having intuitive problems

2 with, with this concept.

3 Alan: Yeah, this is tough.

4 S2: With like, it seems so simple. ???

5 stuff. Well, there's gravity is pulling it

6 down.

7 Alan: Right.

$8 \mathrm{~S} 2$ : And then there's, is there a normal

9 force acting up? Or is that-

10 Alan: Yup.

11 S2: -acting down now.

12 Alan: Mmmm. Right, this is the hard

13 thing. So, yeah, sure, there's a force of

14 gravity down -

15 (Another TA interrupts. Alan leaves to

16 talk to a different group and then

17 comes back. The interruption lasts 1.5

18 minutes.)

19 Alan: Okay, getting back, yeah, so

20 there's a force. If something is going

21 to move in a circle.

22 S1: Yeah.

23 Alan: There needs, there's a force on
24 it, it's the centripetal force. There's a

25 centrifugal acceleration.

26 S2: Right.

27 Alan: So this acceleration is given, is

28 because the velocity vector is changing

29 direction. So there must be an

30 acceleration on it.

31 S1: Right, right.

32 S2: Is that 'cause of kinetic energy, or?

33 Alan: It's related to kinetic energy.

34 But, so, in the case of the roller

35 coaster, the thing is going to move in a

36 circle like this. There always needs to

37 be an acceleration on it. Do you buy

38 that

39 S2: Yeah.?

40 Alan: And that acceleration better not,

41 ??? the centri-centrifugal acceleration.

42 S2: Right.

43 Alan: The one than goes like $v$ squared

44 over $r$. Do you guys remember that

45 one?

46 S1: Yeah.

47 S2: Yeah, yeah, yeah.

48 Alan: So if that, if that is ever zero, it

49 will stop moving in a circle. But you

50 want it to keep moving in a circle.

51 S1: Right.

52 S2: Oh, that's ???

53 S1: Okay.

54 Alan: Try to use that and see how far

55 you get with that. I mean, yell at me if

56 it still makes no sense, okay? But

57 that's sort of the observation. For

58 something to move in a circle, which is

59 what you want it to be doing, it better

60 have $v$ squared over $r$.

61 S2: Okay.

62 Alan: Sort of, um, that better not be

63 zero.

64 S2: Or it'll fall.

65 Alan: It'll fall.

66 S2: Right.

67 S1: Okay.

68 Alan: I mean, it could be, it could be

69 small. It can't be zero.

\section{Alan's frame: Giving students a hint}

Alan is again focused on indicators, but he has a different purpose in this episode than in the previous one. In this instance, Alan is looking for indicators that the students understand what he is explaining to them. This focus on indicators is a subroutine within his larger goal of giving the students a hint. The indicators the students provide include affirmations (such as "okay" and "right") and correctly stating a physical consequence if a certain force is zero.

At the start of the clip, the students call Alan over and S1 explains that he does not know how to do this problem. Alan's response is to provide the two students with informa- 

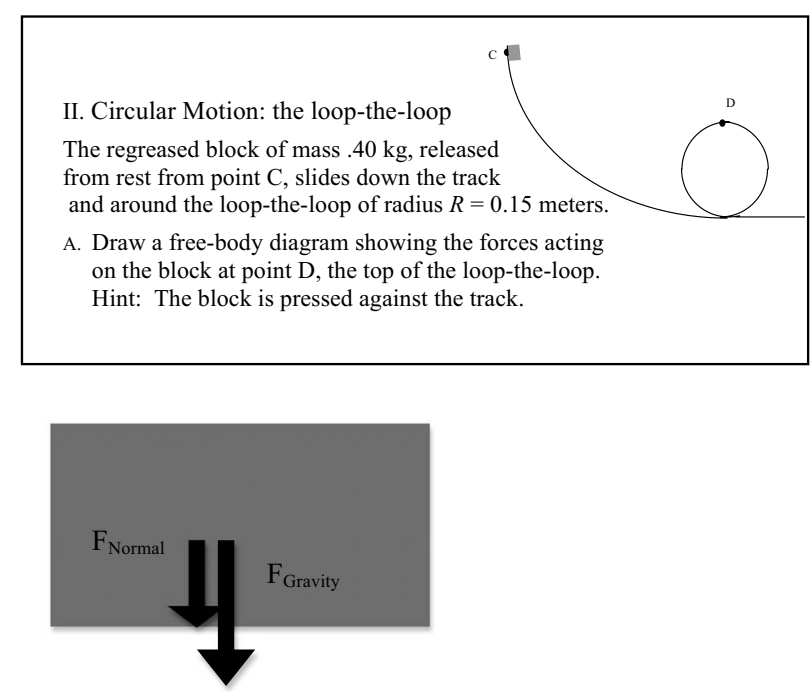

FIG. 2. An excerpt from a tutorial on energy and one possible free-body diagram of the block at point D.

tion that he thinks will help them. When he explains that an object moving in a circle always experiences a centripetal acceleration, Alan considers this to be a reminder of knowledge they already know: he refers to it as the " $v$ squared over $r$ " acceleration and then asks, "Do you guys remember that one?" (lines 44-45). By focusing their attention on the acceleration, Alan may be expecting them to then connect this to the relationship of forces and accelerations represented in the formula $\sum \vec{F}=\vec{F}_{\text {Gravitational }}+\vec{F}_{\text {Normal }}=m \vec{a}$. While it is not exactly clear what Alan expects them to do next (or even if he has a particular path in mind), one way that the directions of individual forces can often be determined is by using the idea that the direction of the net force is the same as the direction of the acceleration. In any case, he is giving them information that he thinks they can use to determine the correct answer.

Alan's affect during this episode is friendly, conveying his desire to help. He speaks in a relaxed manner and makes eye contact with S2 often. While he is talking about circular motion, he frequently gestures, moving his hand in circular gestures that are expansive. He moves around often, which conveys a feeling of energy and perhaps restlessness. He reassures them that their trouble is reasonable, saying, "This is tough," and "This is the hard thing" (lines 3, 12-13). His tone and body position support the idea that he is trying to assist the students by giving them a hint.

During his explanation, Alan seems to be looking for (and receiving) indicators that the students understand what he has told them. These indicators come in the form of affirmations: for example, they acknowledge that they remember the " $v$ squared over $r$ " acceleration (lines 51-52). Later, S2 correctly points out a physical consequence of zero acceleration on a loop-the-loop (line 64). Another indication that Alan is focusing on whether the students understand his explanation is his response to S2's question, "Is that 'cause of kinetic energy, or?" (line 32). (An object's kinetic energy would not help you determine whether or not it has an acceleration.) Another TA might have viewed this question as evidence that the student thinks that the object's kinetic energy causes the acceleration, whereas Alan seems to view it as a minor error that is easily dismissed. Alan's failure to notice that S2's question could signal deeper confusion is further evidence that Alan is framing this activity as giving a hint and paying attention only to whether the students understand his hint. Thus, once the students have provided enough indicators that they understand him, Alan ends the conversation.

\section{One of Alan's beliefs: Instructors should help students grapple with traditional problems}

In many instances of Alan's teaching that we have watched, he states the answer to the students. A typical example occurs when a group of students calls Alan to check their explanation of what kind of motion is represented on the position-time graph in Fig. 3 [[46], p. 691]. The students begin by correctly noting that the first part of the curved line could represent someone running forward who is at first getting faster. They then identify the straight part of the line (where the slope is constant) with "and then you're actually decelerating at a constant speed." Alan interrupts them, saying "Hold on, this is a position graph, so you're not decelerating, I mean you're just changing direction. You're coming back to where you started." The students agree, and then he continues, saying, "You pass zero, past your starting point... and then you stop." Alan often points out mistakes that students have made and corrects them. His action and tone convey the attitude that the students have just made a small error, and that he has confidence that they would have had the correct answer if they had avoided the minor mistake.

In the loop-the-loop episode, Alan's behavior is more nuanced: he directly gives the students information at certain points but does not tell them the final answer. At the start of the conversation, Alan verifies that there is a force, although he is not definite about which direction it points (lines 10 , 19-20, 23-24). He identifies this as the centripetal force, and associates it with the centrifugal acceleration (lines 24-25). He then explains the evidence that there is an acceleration (that the velocity is changing) and that it is the acceleration given by " $v$ squared over $r$ " (lines 28-29 and 43-44). This contrasts with the problem of actually determining which forces will be in the free-body diagram, which Alan does not solve. There are several indications that he expects this question to be difficult for students: he remarks that this is "tough" (line 3) and "hard" (line 12) and he acknowledges that they may end up needing more assistance from him (lines 54-56).

Alan's decision as to whether to provide answers may be influenced by his opinions about whether the particular problem is difficult or not. In our analysis of the previous episode, we discussed Alan's belief that tutorials were too easy for his students. In that episode, Alan seemed to assume that the students understood the problem, which is aligned with his belief that conceptual problems are rarely difficult. In this episode, the students are working on a more typical quantitative physics problem, and Alan's assistance (rather than assumption of the correct answer) is aligned with his idea that students have difficulties with what he called "traditional physics." 


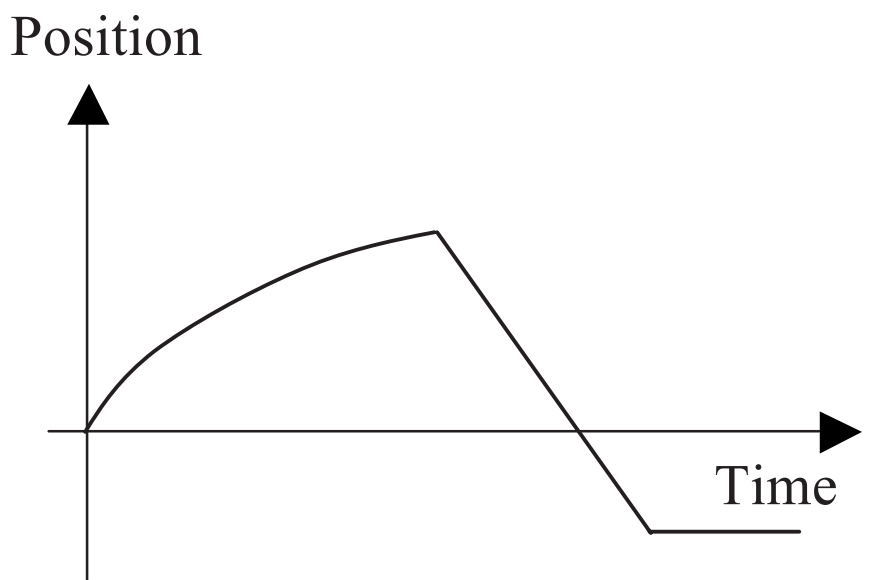

FIG. 3. Excerpt of a tutorial on acceleration.

Alan's specific instructional choices are also influenced by his beliefs about what students can do and how he should treat them, which are summed up by his desire to "give students the benefit of the doubt." When students ask a question, Alan gives them the benefit of the doubt by assuming that they have worked to understand the problem and thus that they deserve an answer. If the issue is conceptual, he usually considers it appropriate to give them information directly. He focuses on affirmations such as "okay" and "right" as evidence that they understand, even though we might not consider these responses convincing. In the case of the freebody diagram, however, Alan refrains from telling them the answer, perhaps because drawing free-body diagrams is more closely aligned with his ideas about what students should be doing in a physics class and therefore he sees it as something they can productively struggle with.

The stability in this episode arises from the expectations of the TA and students, who may not frame the activity in precisely the same way, but who have expectations that at least do not contradict each other. Alan comes to the table believing that it is important for instructors to support students' correct answers. This makes him likely to listen for indicators that the students understand what he is telling them. Students provide those indicators-in this case, verbal affirmations such as "yeah yeah." While these may indicate understanding, they may also be signs of some other positive experience, such as receiving information that they expect will be helpful. Whatever the students' intentions, Alan's belief that the material is straightforward and his judgement that the students understand are not challenged. This sets up a locally coherent situation, which only ends when Alan is finished giving his hints.

Both this clip and the earlier clip are examples of Alan using indicators to determine when students have appropriate knowledge. His responses in the two instances, however, are motivated by two different pedagogical values. In this episode, rather than giving students the benefit of the doubt, Alan acts on his belief that students can and should productively struggle with more traditional physics problems. His instructional choices depend on whether the students indicate that they understand and whether Alan thinks it is a worthwhile and challenging question.

In both of the above episodes of Alan's teaching, Alan focuses on relatively superficial signs that students under-

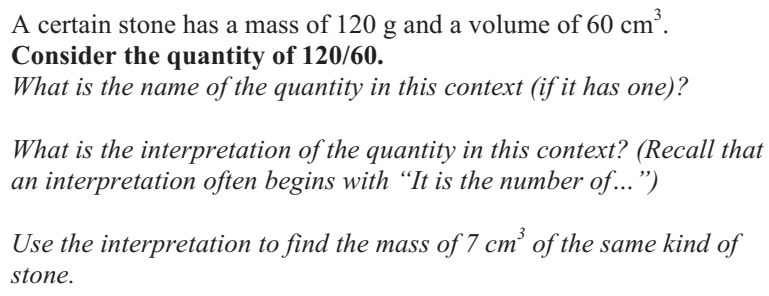

FIG. 4. Excerpt from a tutorial on the properties of matter.

stand. In the first case the indicator is the correct answer and in the second case the indicators are student affirmations. In both cases, Alan's framing of the activity and his behaviors are supported by a set of beliefs: students find conceptual physics problems relatively easy; students have much greater difficulties with formal problems; and a teacher owes it to his students to give them the benefit of the doubt that they have struggled with a problem before calling him over. His specific instructional choices in the two episodes are different, which is probably due to the varying circumstances. In the first episode, Alan probably expects that students most likely already have a solid conceptual understanding, so he just needs to check their answer. In the second episode, the students are working on a more formal problem; this likely activates his belief that students have more trouble with (and a greater need to learn) traditional problem solving, so he supports this process without giving them the answer. In these two examples, we see that a TA with similar focus-onindicator behaviors is motivated by different aspects of his underlying values for tutorial teaching in different episodes. In the following examples, we document other focus-onindicator behaviors and the beliefs that accompany them.

\section{Julian focuses on indicators: Instructionally targeted explanations}

In the next example, a TA again seems to be focusing on indicators, but in this instance both the indicators and the way he helps the students fill them in are different. This episode takes place in the ninth tutorial, and the TA is Julian, a first year graduate student. His students are working on a problem (shown in Fig. 4) that asks for an interpretation of a number [48]. Several tutorials have asked students to provide an interpretation of a calculated number, which is described as "a statement that tells you what the number means physically [3]." In the following example, an acceptable interpretation of the number 2 would be "the number of grams in each cubic centimeter of stone." The tutorial is scaffolding the idea of portioning out the grams to each cubic centimeter, or "package reasoning." Thus, to find the mass of $7 \mathrm{~cm}^{3}$ of stone, one may imagine seven one-cubic-centimeter pieces of the stone; since each piece has two grams of stone, the mass of the $7 \mathrm{~cm}^{3}$ piece is $14 \mathrm{~g}$.

An alternative means of determining the mass of the stone is to use the formula density=mass/volume. While this method is also correct, it can support routine application of an algorithm rather than a thoughtful conceptualization of the properties of matter. For this reason, the tutorial's focus 
is on helping students construct and use interpretations of calculated numbers rather than formulas [49].

The interaction below occurs after the students have called Julian over to ask a different question. Julian asks them how they used the interpretation of density. He suggests that their original answer uses the equation instead of their interpretation, and after verifying their interpretation he guides them in phrasing their answer so that it uses their interpretation in the way the tutorial expects. (Speech turns that overlap are bracketed by the symbols [\rfloor .)

1 Julian: So, how did you use your

2 interpretation for the density to

3 determine how much mass the object

4 has?

5 S3: Ah, you mult-, er, calculate the

6 ratio of mass over, yeah, mass over

7 volume, and multiply the volume by

8 the, by the density and you get the-

9 Julian: I don't know if that really uses your

10 interpretation. That sort of more uses

11 an equation.

12 S3: Oh, okay.

13 Julian: So you know, so you're sort of

14 saying you know density is this, so

15 you're trying to find a mass that

16 satisfies this density. But that's not

17 really using your interpretation.

18 S3: Grams and centimeters, so...

19 Julian: So, how would you go about using

20 your interpretation?

21 S3: Well, you need the number of

22 grams, number of grams in seven

23 centimeters and density's, I don't

24 know. I'm not sure how to explain it

25 without using the equation.

26 Julian: So what is your interpretation, first

27 of all?

28 S3: Number of grams, uh, in a cubic

29 centimeter.

30 S2: Stuff in an amount of area.

31 Julian: Okay, so there's two grams per

32 cubic centimeter, is that what you're

33 saying?

34 S3: Right, yeah.

35 Julian: So, I think it's more of a-

36 S3: Okay.

37 Julian: two is the number of grams per

38 cubic in a cubic centimeter for an

39 object.

40 S3: To get seven cubic centimeters,

41 you have, there's two... two grams for

42 every cubic centimeter.

43 S4: [Sorry.]

44 Julian: [Right.]So that would be a good

45 way to think about it, [except, well-

46 S5: [Better be.]

47 Julian: -a good way [to use your

48 interpretations is that-]

49 S4: [Not anymore.]
50 Julian: -is that so, for ever-you have

51 seven cubic centimeters. And for

52 every cubic centimeters you're going

53 to have two grams. So you're going to

54 have two, four-seven two-gram units.

55 So, so that the total's fourteen grams.

56 [Julian leaves the table.]

\section{Julian's frame: Guiding students to the instructionally targeted answer}

In this episode, Julian is looking for what he takes to be the instructionally targeted answer, for both the interpretation itself and in the way the interpretation is used to solve a problem. There is evidence of this from the beginning, when he tells S3 that his answer does not use the interpretation as Julian expects (line 9-11, 16-17). The fact that Julian is focused on what the students are not doing is strong evidence that he is looking for something in particular.

When S3 seems unable to offer an answer Julian would find acceptable (lines 18, 21-25), Julian backs up and asks what their interpretation is. Here he also looks for the instructionally targeted explanation. S3's reply of "Number of grams in a cubic centimeter" (lines 28-29) is close to the ideal answer because it is consistent with the idea of package reasoning (portioning out the grams to each cubic centimeter) that the tutorial developers want students to use. But Julian does not find this adequate, as signaled by the phrase "So, I think it's more of..." (line 35) followed by his offer of the correct answer in lines 37-39. This same pattern is repeated when S3 tries to use the interpretation by applying it to seven cubic centimeters of stone (lines 40-42): he appears to be very close to the correct answer, but Julian again signals a correction with "Except, well, a good way to use your interpretations is..." (lines 45, 47-48) followed by the answer.

Lastly, when he thinks that he cannot lead students to the right answer, he states the answer (lines 50-55) and then leaves the table. This indicates that Julian perceives his job at this moment to be done. The students have the right answer, although he had to present it to them. In a way, Julian has provided his own indicator.

Often when TAs focus on indicators, it leads them to be too generous with attributing understanding, as we saw in the examples with Alan. In this case, however, Julian has stricter criteria for a "good answer" than the tutorial developers desire. S3 demonstrates ideas that suggest he is making progress toward the right answer (lines 28-29 and 40-42) but they do not use the wording that Julian wants. S3's answer, "Number of grams in a cubic centimeter" is actually closer to the tutorials developers' targeted explanation than Julian's rephrasing of "per cubic centimeter;" including the word "per" often indicates a rote memorization of the density definition rather than a successful use of package reasoning, which was a point stressed in the TA training meeting the week before. Julian's attention is on the precise wording that he expects in the correct answer. He provides this precise wording twice, failing to notice that S3's answer is well aligned with the instructionally targeted answer. 
The students in this episode might characterize what they are doing as "checking their answer" or see Julian as "helping them get the answer," a framing that does not conflict with how Julian has directed the conversation. For example, Julian asked about their interpretation, establishing the topic for the conversation, even though the students originally called Julian over. Likewise, S3 and S2 try to answer Julian's questions (lines 5-8, 21-25, 28-29, 30), thus indicating that they are willing to pursue the topic and direction established by Julian. In addition, S3 attempts to apply Julian's interpretation (lines 40-42), demonstrating that he is trying to make sense of what Julian said. Therefore, when Julian tries to nudge the students toward the answer he wants, the students cooperate and do not offer challenges, and a locally coherent situation is established.

\section{One of Julian's beliefs: TAs should ensure that students have the right answer}

The beliefs and attitudes Julian expresses in his interviews about the tutorials connect to his valuing the instructionally targeted explanation in this example. In his interviews, Julian frequently talks about the importance of students having the right answer when they are done with the tutorial and the idea that his job as a TA is to make sure they have that answer. He worries that the tutorial can harm students when it does not provide a way for them to check their answer, such as when "there's no, like direct answer and students get worried because like they're working together in a group... They may all come to the wrong conclusion and so like they have no way of knowing that their conclusion is wrong."

He thinks it is his job to help get students to the right answer, but that this has to be done carefully: "I think the best way is to start from where they're thinking and try to lead them to where you're thinking... Go step by step from their point of view to your point of view." Guiding the students in little stages is important because, "If I get them to think about it first and then talk to me about it, then they will have to stop and then try to realize what the question was rather than just hear the answer and then move on to something else." Julian's belief is well aligned with a constructivist philosophy; it goes awry here for the subtle reason that his view of what constitutes a good answer is narrow.

His behavior in the previous segment is consistent with his beliefs in the importance of the correct answer and student construction of that answer. If the students do not have the correct answer, then they need to learn it before he leaves the table. He attempts to elicit the correct answer from the students, an action that aligns with his belief that students should construct their own answers. When this fails, however, he tells the students the answer. In this moment, it may be that his belief that students need to have the right answer when they are done is more central than his belief that students should construct their own knowledge.

In the example discussed, Julian sees the correct answer as the version of the interpretation that was discussed in the TA preparation meeting. Interpretations are usually tricky for TAs to teach, because they require a particular articulation of reasoning that is unfamiliar to both students and TAs. In this case, Julian may not have considered any other ways stu- dents might demonstrate the instructionally targeted understanding other than the particular formulation that he developed during the TA meeting. Thus, Julian helps the students by leading them with his questions to the answer he thinks they need to have.

\section{Oscar focuses on indicators: Answers to canonical questions}

The final example comes from Oscar, a second year graduate student who was teaching tutorials for the third time during the semester we taped him. The conversation discussed below occurs approximately halfway through a tutorial in the eleventh week on ideal gases [47]. The students have completed the tutorial and are talking off-topic when Oscar notices that they are done and comes over. This is the first time a TA has talked to the group during the tutorial session, and Oscar uses it as an opportunity to review all their work. This episode shows the first two and half minutes, in which they discuss the content of the first page, which is part of a ten-minute discussion of the whole tutorial. The start of the worksheet, shown in Fig. 5, presents a container filled with an ideal gas at a pressure of one atmosphere and held in by a heavy lid that is free to move up and down. The students are asked whether the lid will hold the gas in or whether it is "on the brink" of letting the gas out; the correct answer is that the combined forces of the lid and of the air above (also at one atmosphere) will definitely hold the air in.

Oscar begins this interaction by asking the students how much gas they could put in the container without holding the lid on, which is the last question on the page (question B, also shown in the figure). The expected answer is that you would need to know the weight of the lid, but that the maximum pressure would be greater than one atmosphere. The students answer with "one a.t.m." (atmosphere) and Oscar accepts this answer. Oscar has apparently forgotten that the lid has mass, because this is only true if the lid is massless. He then goes on to ask them how they could put more gas in, and continues to question them until they establish that the volume of the container would have to be increased to contain additional gas.

1 Oscar: You guys are done?

2 S4: Yeah.

3 S1: Pretty much. Woo-hoo.

4 Oscar: All right. So, um, go back a

5 page. Go back another page. What

6 does that say?

7 S4: Oh, ??? first page.

8 Oscar: All right, well, okay. So you

9 guys, you guys already have the

10 benefit of knowing what's to come.

11 So, what's the point of this here?

12 Okay, what's the result? How much

13 gas can you put in there without

14 holding, um, holding the lid on?

15 S3: Uh, one a.t.m.

16 Oscar: Why?

17 S3: Cause there's one a.t.m. on the

18 outside, so it balances out. 
19 Oscar: How could you, uh, put more

20 than one atmosphere in there?

21 S3: The lid would have to weigh more,

22 I guess, the mass of the lid.

23 Oscar: That's one way.

24 S3: Temperature, also.

25 Oscar: What could you, what could

26 you change about the, uh, about the,

27 uh, container?

28 S3: Increase the volume?

29 Oscar: Right, and how could you do

30 that?

31 S3: Uh, the height of it?

32 Oscar: Yeah.

33 S3: Increase the height of it?

34 Oscar: So if there are two, so if the

35 sides of the cylinder went up a lot

36 farther, there are two atmospheres in

37 here, one atmosphere outside, what

38 would happen?

39 S3: You could have more, it would

40 allow for more, um, pressure inside.

41 Oscar: Right. So you have more, so

42 what would happen? Does the lid

43 move?

44 S1: Yeah.

45 Oscar: Why?

46 S1: Cause there's more pressure on the 47 inside.

48 Oscar: Right. So how does it move? So

49 it moves up a little bit and what

50 happens?

51 S3: It stops and ???.

52 S1: Yeah.

53 Oscar: When does it stop?

54 S3: Um-

$55 \mathrm{~S} 1$ : When it equalizes.

56 S3: Yeah.

57 Oscar: Okay. And when is that?

58 S3: When-

59 Oscar: How much does the volume

60 Have to increase by?

61 S1: One at-, er.

62 S3: Uh.

63 S1: What does it have to increase by?

64 Oscar: Yeah. How much does the

65 volume have to increase?

$66 \mathrm{~S} 3$ : Is it, is it inversely, as the pressure

67 goes up?

68 Oscar: What is? PV $=\mathrm{nRT}$.

69 S3: Yeah.

70 Oscar: You're given that formula,

71 right. So if, so you have initially, uh,

72 two atmospheres and one volume.

73 S1: Mm-hmm.

74 Oscar: So you want one volume-

$75 \mathrm{~S} 1$ : So it would be twice as much.

76 Oscar: Right. Twice as much. Okay.

77 So, go on to the next page.

\section{Oscar's frame: Steering students' canonical physics reasoning}

In this episode Oscar asks questions about two different physical problems. The first conversational segment (lines 1-18) concerns a container of ideal gas with a moveable massless lid; the question he is asking is, "How much gas can you put in the container without holding the lid on?" The second conversational segment (lines 19-75) starts with the same physical setup, but now the question is, "How can you alter the setup so that the container will have a higher pressure?" We characterize these questions as "canonical" because they are questions commonly found in introductory physics textbooks.

The first conversational segment is puzzling because Oscar seems to be asking question B in the tutorial, but he accepts S3's answer of "one a.t.m." as correct (lines 15-16). This implies that Oscar is picturing a container of ideal gas with a massless piston lid. (S3's answer would be correct if the lid had no mass and the outside pressure was one atmosphere.) This is similar to, but not precisely the same as, question B with the heavy lid. Oscar may not have noticed this difference because idealizing a lid as massless is common in ideal gas questions. Oscar's mischaracterization of the problem, which is probably unintentional, is evidence that he framing the situation as solving canonical physics problems.

The second conversational segment offers multiple pieces of evidence that Oscar is seeking a particular answer. For example, the students offer two potentially correct answers to his initial questions: if the mass of the lid was increased or the temperature of the gas was decreased more gas would fit inside the same volume. The students' answers could lead in these directions (lines 21-22, 24) and both times Oscar indicates that those answers are not the ones he is looking for by prompting them for an additional answer (lines 23, 25-27). Next, Oscar indicates that he approves of some answers by affirming them and asking a new question that builds on the previous answer (lines 29-30, 41-43, 48-50, 57), with statements like "Right, and how could you do that?" (lines 2930). Additional support for the idea that Oscar is seeking particular answers is that these are guiding questions, such as "Does the lid move?" (lines 42-43) and "When does it stop?" (line 53). These questions constrain the students' responses because the required answers are brief words or phrases.

Oscar is using an answer with particular reasoning as an indicator of understanding in the second part of this episode. His guided questions help the students figure out which answer he would like to hear at each point, until they answer the original question, how more gas can be put in, with the particular answer of "the volume must be increased." They then must apply this knowledge to the particular question of how much the volume would need to increase to contain twice as much gas (lines 70-75).

The tone and pace of Oscar's conversation, along with his body positioning, provide clues to how he is framing this interaction. He speaks louder than any of the students and when he gives directions to turn the pages, his tone is commanding (lines 4-5). The majority of Oscar's speech turns occur immediately after the previous student turn, sometimes 


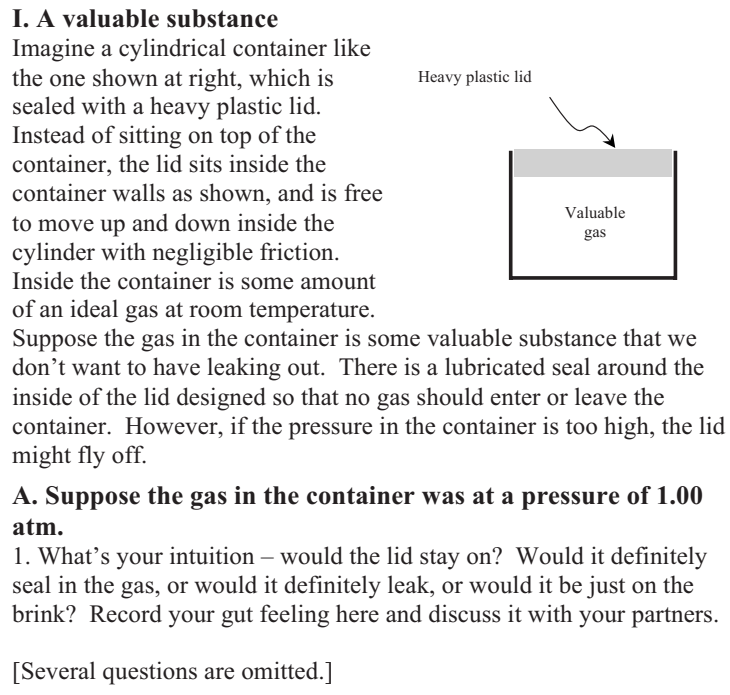

A. Suppose the gas in the container was at a pressure of $\mathbf{1 . 0 0}$ atm.

1. What's your intuition - would the lid stay on? Would it definitely seal in the gas, or would it definitely leak, or would it be just on the brink? Record your gut feeling here and discuss it with your partners.

[Several questions are omitted.]

B. What maximum pressure could the lid sustain without anyone holding it in place? What would you need to know about the apparatus in order to calculate a numerical value for the maximum pressure?

FIG. 5. Excerpt from a tutorial on the ideal gas law.

even starting before the student is finished speaking, whereas there is a noticeable pause after his questions before a student speaks. This contributes to a feeling that Oscar is setting the pace for the conversation, and that this pace is faster than the students are going. There is no chance for the students to ask questions, unless they would ask a question in place of answering one of Oscar's questions, because as soon as a student has finished speaking, Oscar poses another question. When he approaches the table, Oscar leans forward and firmly grips the sides of the table, as seen in Video 1 . He continues this during the entire episode, letting go only when he gestures. His hips sometimes rock from side to side, but his hands and feet generally remain firmly positioned. This posture corresponds to the way Oscar is framing. He is leading the conversation, steering the students to the correct answers, and tightly controlling the acceptable responses. (A portion of this video can be seen in Video 1).

The students' responses help sustain the way Oscar is framing this activity. The answers they give are short and do not introduce any information beyond what he has requested. Although it appears that they are not always certain which

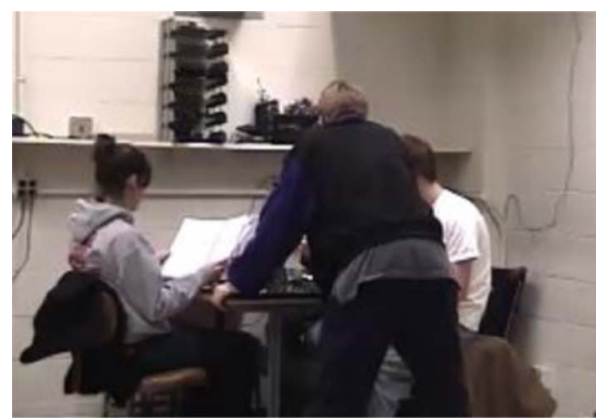

Video 1 (Color) Posture during the conversation. answer he would like, they keep offering answers until Oscar accepts one of them. They also do not introduce questions of their own which might change the direction of the conversation. (The only student question occurs at line 63, which is a paraphrase of Oscar's question.) The students cannot know what answer Oscar wants because they (and we) do not know what situation he is picturing. In fact, we can only figure out afterwards what Oscar is thinking about by considering what answers he accepts as correct. The fact that the students are willing to offer answers about a situation that they probably cannot make sense of is further evidence that they are allowing Oscar to direct the conversation.

Oscar's attention to answers of canonical questions is a locally coherent activity, which is a larger part of the guided questioning he uses to direct the conversation toward canonical physics reasoning. The focus on indicators appears as a simple loop, in which an unacceptable student answer leads to Oscar reasking the question and an acceptable student answer (which is the indicator Oscar seeks) leads to the next loop. The students' behavior does not challenge this pattern, so it remains coherent during the episode.

Both of the physical situations that Oscar introduces during this episode are typical situations found in physics textbooks. Neither of the situations comes directly from the tutorial. The first is a modified version of the tutorial question $\mathrm{B}$, and is noteworthy because Oscar does not indicate that he notices that he has modified the question. The second is more obviously a problem that he is introducing. The similarity in both of these sets of questions is that they focus on the relationship between variables in equations. That is, Oscar is thinking about the equation $P V=n R T$ and directing the students' attention to how these different variables (and the quantities they represent) relate to one another. The next section will discuss why we think Oscar focuses on these relations.

\section{One of Oscar's beliefs: TAs need to get students going in the right direction}

We have observed that Oscar often attends to the idea of how variables relate when talking to students. In one example [50], a group of students are considering a situation in which a $2000 \mathrm{~kg}$ truck collides with a stationary $1000 \mathrm{~kg}$ car. They are told that the truck slows down by $5 \mathrm{~m} / \mathrm{s}$ and then asked to figure out the new speed of the car. The students tell Oscar their answer is $10 \mathrm{~m} / \mathrm{s}$, which he confirms. They support their answer by the reasoning that the car's mass is half as much as the truck's, which we would consider an acceptable answer. Oscar asks for further reasoning, eventually using guided questioning to prompt them to say that the forces that each object experiences must be the same, and since the masses are different, the accelerations will also be different. During the discussion, Oscar declares, "The basic problem in pretty much every last physics question you'll ever answer is to figure out what's the same and what's different. Either before or after." This statement, along with his questions centered on the $F=m a$ equation, show that Oscar is focusing on the relationships of variables in equations.

In his interviews, Oscar stressed the need for students to be given a context for the problems they are working on. $\mathrm{He}$ 
said, "Sometimes I felt... they really just need to be given the answer. If they're just given the answer, you know, they know what to work towards, and maybe that's the bigger picture they need. Seeing how one thing leads to another." He did not think that the tutorials did this on their own: "Sometimes, since they're [the students] left to their own devices, they can go off in different directions." He was concerned that students were given too much freedom to follow different lines of reasoning and thus would not learn the concepts they were supposed to learn. Oscar also expressed reservations about the usefulness of tutorials for his students; he disagreed with the tutorials' focus on qualitative understanding and connecting this to their common sense intuitions and felt that students would be better served by constructing meaning through using equations.

He also thought he had improved in his ability to ask questions that provide the needed context to students. Oscar chose to teach introductory courses for nonmajors repeatedly because he thought that his initial experience teaching tutorials had better prepared him to ask students questions that could help them. When he was explaining why he had volunteered to teach tutorials a second time, Oscar said, "I suppose at the beginning I think I did a lot more rephrasing their own question to me... Whereas now I think I'm much more capable of phrasing a question that still gives them some information and points them much better in the right direction." This statement shows that Oscar has deliberately chosen to disregard the instructions he received during tutorial preparation meetings to reflect the students' question back to them. His intentional decision to use strongly guided questions is not aligned with the tutorials' philosophy, but his reason for this choice is admirable: he thinks these questions help students more.

By asking students about canonical physics situations and expecting them to reason about the relationships of physical quantities, Oscar is providing a context for the new conceptual knowledge students are acquiring. This is something he considers an important part of learning physics, and something that he feels the tutorials are not accomplishing.

\section{IMPLICATIONS FOR PROFESSIONAL DEVELOPMENT}

The identification of the pattern of "focusing on indicators" leads to the question of how TA professional development (PD) could better address this behavior. One seemingly plausible intervention would be to instruct TAs in the importance of completely eliciting and understanding student ideas. We argue, however, that this would be just as ineffective as our previous instruction to ask the students questions, if the beliefs underlying the behavior are not addressed.

Asking TAs to alter some of their beliefs about teaching and learning is asking them to make a significant change in how they think about an activity that they have participated in for over a dozen years. We suspect that the activities that we will suggest would be effective primarily as part of a larger, sustained PD program. Such a program would likely need to include multiple opportunities for TAs to practice applying the ideas and methods they learn, as well as selfreflection and formative assessment about their teaching from their peers and TAs instructors. The goal of such PD would not simply be belief change, but a change in beliefs that is connected to changed classroom practice.

That said, we can imagine some activities that might be effective as part of the larger program we think is necessary for effective PD. To better understand how PD might focus on TAs' beliefs, consider the example of Alan. In the first episode that we presented, Alan's focus on indicators stemmed from his belief that instructors should give students the benefit of the doubt. An activity that addresses this belief might involve having TAs watch video of students discussing their answers. The TAs could be asked to describe the students' ideas and assess their correctness after a small portion of the episode is watched and again after the students have fully discussed their reasoning. Our experience is that most people, including TAs, readily recognize the richness of student ideas when given the opportunity to reflect on and discuss them. Such an activity would provide the TAs with an opportunity to experience how only seeing a small portion of a student's reasoning can prevent TAs from recognizing interesting or problematic ideas students might have. The insight would die on the vine, though, without multiple opportunities for the TAs to relate that experience directly to their own classroom practice.

\section{CONCLUSION}

Fine-grained analysis of TAs' teaching contributes to the effective design of professional development programs. In order to help TAs grow as instructors, we need to understand not just what decisions TAs make, but why they make them. The three TAs we discuss here all focus on indicators at one level, but are all doing different things at a finer-grained level. Furthermore, when we investigate the beliefs that underlie these behaviors, we find that they vary for each TA. Triangulating between these fine-grained behavioral observations and the beliefs that underlie the behaviors allows us to gain the deeper, more respectful understanding of TAs that is needed to inform their PD.

The recognition that TAs can focus on indicators provides an opportunity for professional development instructors to help TAs become aware of the strengths or weaknesses of various student knowledge assessments. This analysis shows that there are many ways TAs can frame their teaching that utilize the locally coherent "focus on indicators" behavior. Attending to these larger frames may help TAs become aware that focusing on indicators prevents them from attending to the substance of students' thinking.

\section{ACKNOWLEDGMENTS}

This material is based upon work supported by the National Science Foundation under Grants No. NSF REC 0529482 and No. 0715567. 
[1] P. Heller and M. Hollabaugh, Teaching problem solving through cooperative grouping. Part 2: Designing problems and structuring groups, Am. J. Phys. 60, 637 (1992).

[2] E. Mazur, Peer Instruction: A User's Manual (Prentice-Hall, Upper Saddle River, NJ, 1997).

[3] L. McDermott, P. Shaffer, and the Physics Education Group at the University of Washington, Tutorials in introductory physics (Prentice Hall, Upper Saddle River, NJ, 2002).

[4] D. Sokoloff and R. Thornton, Interactive Lecture Demonstrations, Active Learning in Introductory Physics, Interactive Lecture Demonstrations, edited by David R. Sokoloff and Ronald K. Thornton (Wiley, New York, 2004) p. 374.

[5] K. Adams, Preparing Future Faculty Occasional Paper (Association of American Colleges and Universities, Washington, DC, 2002) p. 2005.

[6] J. Carroll, Effects of training programs for university teaching assistants: A review of empirical research, J. Higher Educ. 51, 167 (1980).

[7] C. Golde and T. Dore, At Cross Purposes: What the Experiences of Doctoral Students Reveal About Doctoral Education, 2001, Pew Charitable Trusts. www.phd-survey.org: Philadelphia, PA.

[8] L. McDermott and E. Redish, Resource letter: PER-1: Physics education research, Am. J. Phys. 67, 755 (1999).

[9] L. McDermott and P. Shaffer, Research as a guide for curriculum development: An example from introductory electricity. Part I: Investigation of student understanding, Am. J. Phys. 60, 994 (1992).

[10] A. Kezar and P. Eckel, The effect of institutional culture on change strategies in higher education: universal principles or culturally responsive concepts?, J. Higher Educ. 73, 435 (2002).

[11] D. French and C. Russell, Do graduate teaching assistants benefit from teaching inquiry-based laboratories?, BioScience 52, 1036 (2002).

[12] P. Hammrich, National Conference on College Teaching and Learning (unpublished).

[13] C. Ishikawa, W. Potter, and W. Davis, Beyond this week's lab: Integrating long-term professional development with shortterm preparation for science graduate students, J. Grad. Teach. Assist. Dev. 8, 133 (2001).

[14] F. H. P. Lawrenz, R. Keith, and K. Heller, Training the teaching assistant: Matching TA strengths and capabilities to meet specific programs goals, J. Coll. Sci. Teach. 22, 106 (1992).

[15] E. Price and N. Finkelstein, arXiv:physics/0609003 (unpublished).

[16] E. Etkina, Helping graduate assistants teach physics: Problems and solutions, J. Grad. Teach. Assist. Dev. 7, 123 (2000).

[17] K. Hollar, V. Carlson, and P. Spencer, $1+1=3$ : Unanticipated benefits of a co-facilitation model for training teaching assistants, J. Grad. Teach. Assist. Dev. 7, 173 (2000).

[18] C. Ishikawa et al., in Meeting of the National Association for Research in Science Teaching (unpublished).

[19] L. Bryan, Nestedness of beliefs: Examining a prospective elementary teacher's belief system about science teaching and learning, J. Res. Sci. Teach. 40, 835 (2003).

[20] D. K. Cohen, A revolution in one classroom: The case of Mrs. Oublier, Education Evaluation and Policy Analysis 12, 311 (1990).

[21] M. G. Jones and G. Carter, in Handbook of Research on Sci- ence Education, edited by S. K. Abell and L. M. Lederman (Lawrence Erlbaum, Mahwah, NJ, 2007), pp. 1067-1104.

[22] K. King, L. Shumow, and S. Lietz, Science education in an urban elementary school: Case studies of teacher beliefs and classroom practices, Sci. Educ. 85, 89 (2001).

[23] K. E. Levitt, An analysis of elementary teachers' beliefs regarding the teaching and learning of science, Sci. Educ. 86, 140 (2002).

[24] P. Simmons et al., Beginning teachers: Beliefs and classroom actions, J. Res. Sci. Teach. 36, 930 (1999).

[25] K. Tobin and C. McRobbie, Beliefs about the nature of science and the enacted science curriculum, Sci. Educ. 6, 355 (1997).

[26] J. McGivney-Burelle et al., Building bridges: Improving the teaching practices of TAs in the mathematics department, J. Grad. Teach. Assist. Dev. 8, 55 (2001).

[27] J. Robinson, New teaching assistants facilitate active learning in chemistry laboratories: Promoting teaching assistant learning through formative assessment and peer review, J. Grad. Teach. Assist. Dev. 7, 147 (2000).

[28] J. Belnap, Putting TAs into context: Understanding the graduate mathematics teaching assistant, in Department of Mathematics. 2005, The University of Arizona.

[29] J. Luft et al., Growing a garden without water: Graduate teaching assistants in introductory science laboratories at a doctoral/ research university, J. Res. Sci. Teach. 41, 211 (2004).

[30] N. Speer, Connecting Beliefs and Teaching Practices: A Study of Teaching Assistants in Collegiate Reform Calculus Courses (University of California, Berkeley, Berkeley, CA, 2001).

[31] E. Redish and D. Hammer, Reinventing college physics for biologists: Explicating an epistemological curriculum, Am. J. Phys. 77, 629 (2009).

[32] A. Elby, Helping physics students learn how to learn, Am. J. Phys. 69, S54 (2001).

[33] A. Elby et al., Maryland tutorials in physics sense-making, DVD, Funded by NSF DUE-0341447.

[34] G. Bateson, Steps to an Ecology of Mind: Collected Essays in Anthropology, Psychiatry, Evolution, and Epistemology (Chandler Press, San Francisco, 1972).

[35] E. Goffman, Frame Analysis: An Essay on the Organization of Experience (Harper \& Row, Cambridge, MA, 1974).

[36] G. MacLachlan and I. Reid, Framing and Interpretation (Melbourne University Press, Portland, OR, 1994).

[37] D. Tannen, Framing in Discourse (Oxford University Press, New York, 1993.

[38] M. Pajares, Teachers'beliefs and educational research: Cleaning up a messy construct, Rev. Educ. Res. 62, 307 (1992).

[39] A. Schoenfeld, Toward a theory of teaching-in-context, Issues Educ. Res. 4, 1 (1998).

[40] J. Aguirre and N. Speer, Examining the relationship between beliefs and goals in teacher practice, J. Math. Behav. 18, 327 (1999).

[41] R. Goertzen, R. Scherr, and A. Elby, Accounting for tutorial teaching assistants' buy-in to reform instruction, Phys. Rev. ST Phys. Educ. Res. 5, 020109 (2009).

[42] N. Brickhouse, Teachers' beliefs about the nature of science and their relationship to classroom practice, J. Teach. Educ. 41, 53 (1990).

[43] L. Cronin-Jones, Science teacher beliefs and their influence on curriculum implementation: Two case studies, J. Res. Sci. Teach. 28, 235 (1991). 
[44] D. Hammer et al., Resources, framing, and transfer, in Transfer of Learning from a Modern Multidisciplinary Perspective, edited by J. Mestre (Information Age Publishing, Greenwich, CT, 2005), p. 89-120.

[45] Assessing Graduate Programs, Program Details, University of Maryland, 2005 [cited 2009 November 25, 2009].

[46] L. McDermott, P. Shaffer, and M. Rosenquist, Physics by Inquiry (Wiley, New York, 1996), Vol. 2.

[47] A. Elby and R. Scherr, Physics 121: Tutorials and Laborato- ries (Wiley, New York, 2006).

[48] Adapted from Section 10, L. McDermott, P. Shaffer, and M. L. Rosenquist, Physics by Inquiry (Wiley, New York, 1996).

[49] A. Arons, Cultivating the capacity for formal reasoning: Objectives and procedures in an introductory physical science course, Am. J. Phys. 44, 834 (1976).

[50] This episode, along with a more detailed examination of Oscar's beliefs about tutorials and their influence on his practice, is discussed in greater detail in Ref. [41]. 